\title{
TRAINING HABITS IN PROFESSIONAL SOCCER PLAYERS DURING COVID-19 CONFINEMENT
}

\author{
Marcos Chena, Luis Gutiérrez-García, Juan Carlos Zapardiel, and Iván Asín-Izquierdo \\ Department of Biomedical Sciences, Faculty of Medicine and Health Sciences, \\ University of Alcalá, Madrid, Spain
}

Original scientific paper

DOI $10.26582 / \mathrm{k} .53 .2 .11$

\begin{abstract}
:
The pandemic caused by COVID-19 has led to an unprecedented situation, forcing governments to take urgent measures and confine the population. These measures have also affected sports. Soccer competitions and training sessions were interrupted worldwide, causing the need to adapt training sessions to the new situation. The objective of this study is to observe and analyse training habits carried out during the COVID-19 confinement by Spanish professional soccer players of both sexes. An observational study was based on an ad-hoc telematic questionnaire during the COVID-19 state of alarm in Spain. The results showed that strength and conditioning training was of great importance in the training habits developed during the COVID-19 confinement, fundamentally that of strength and endurance capacities. Specificity was low as conditional capabilities were affected by contextual limitations. The findings of this study yielded very useful information related to the training habits of professional soccer players of both sexes and offered an unpublished reference database that could be used to address training planning at specific periods of the year (transition, vacations, emergencies, ...), with the aim of resuming competitive activity in the best conditions.
\end{abstract}

Key words: football, isolation, training, coronavirus, COVID-19

\section{Introduction}

Severe Acute Respiratory Syndrome Coronavirus 2 (SARS-CoV-2) is the virus responsible for the coronavirus disease in 2019 (COVID19) (Valencia, 2015). First identified in Wuhan (Hubei, China) in December 2019, it has become the world's top health headline due to causing major public health concerns globally (Chen, et al., 2020; Valencia, 2015). On January 30, 2020, the World Health Organization (WHO) declared a public health emergency on an international scale as cases began to spread around the world (Chen, et al., 2020). An unprecedented pandemic was generated and it forced governments to take "urgent and aggressive measures' to delay and mitigate the peak of infection (Corsini, Bisciotti, Eirale, \& Volpi, 2020). These decisions drastically and forcefully affected everyone, including those engaged in sports. All sports competitions were postponed and any organized training or practice was prohibited (Corsini, et al., 2020; Jukic, et al., 2020). The Tokyo Olympic Games and the European Football Championship were postponed for a year, with the priority being to protect the health of athletes, coaches and spectators (Corsini, et al., 2020).
Government authorities established restrictions on participation in physical-sporting activities, declaring a situation of isolation and mandatory confinement (Chen, et al., 2020). Despite the warnings from the health authorities not to resume sporting activity before the COVID-19 emergency had clearly improved (Corsini, et al., 2020), the claims were that national competitions would resume to end the season without spectators. In another words, the return to normality of training generated a lot of uncertainty, contractual commitments were modified, and European competitions, the start of the following season and the transfer market were delayed.

The transmission of the SARS-CoV-2 virus occurs mainly by a close contact through respiratory droplets (Valencia, 2015) and soccer is a sport that generates close contacts between players during their daily activities and practice, which entails high-risk situations in disease transmission (Corsini, et al., 2020). Although soccer players have a low risk of death from the COVID-19 infection due to their youth and physical condition, this infection could develop severe respiratory failure and safety measures should be increased (Corsini, et al., 2020). 
Despite the fact that isolation has been considered a safe measure to prevent the spread of the virus (Chen, et al., 2020; Corsini, et al., 2020; Jukic, et al., 2020), it brought a negative impact on the physical and mental state of athletes (Chen, et al., 2020; Tavares-Lima, et al., 2020). The effects of detraining on professional soccer players, as a consequence of the substantial reduction in physical activity (Mujika \& Padilla, 2000; Suarez-Arrones, et al., 2019), could be exacerbated due to insufficient and inadequate nutrition, poor quality of sleep (Jukic, et al., 2020) or adopting sedentary behaviours such as spending too much time sitting or lying down (Chen, et al., 2020). This situation has generated the need for the strength and physical conditioning coaches of soccer teams to provide recommendations on healthy lifestyle habits and to prescribe training programs to continue physical activity in the players' home, with the aim of reducing the unintended consequences of this forced confinement (Jukic, et al., 2020). However, this unexpected situation has prevented the athletes from having all the necessary resources to train due to existing highly different contexts among soccer players.

To date, there is no evidence of the training sessions that different professional footballers of both sexes carried out in their homes during the confinement. Therefore, the objective of the study was to describe the training habits of professional soccer players of both sexes during the COVID-19 confinement and compare the results between men and women in order to generate unprecedented knowledge from the athlete's perspective in an exceptional situation.

\section{Methods}

\section{Participants}

In total, 218 professional soccer players (men's first, second and third division; women's first and second division) participated voluntarily accepting the informed consent for this study. The soccer players were divided according to gender: 155 male and 63 female. Male players had a mean age of $26.4( \pm 5.7)$ and $12.4( \pm 5.4)$ years of experience, while female players had a mean age of $22.2( \pm 4.9)$ and $12.3( \pm 5.4)$ years of experience. The sample size was adequate and representative of the studied population. An initial telephone contact was made with the technical managers from the teams so that the questionnaire was provided to the footballers. The questionnaire included a detailed explanation of the study and was created to be answered electronically by the footballers within a set period. The study followed the tenets of the Declaration of Helsinki.

\section{Measures and procedures}

This is an observational study in which the variables were recorded through an anonymous $a d-h o c$ telematic questionnaire (available as an online PDF attachment). It was carried out between April 6 and May 4, 2020, in Spain. The method used was similar to the one used by other observational studies with similar characteristics (McCall, et al., 2014). The questionnaire was designed, agreed on, and evaluated by an expert committee. This committee was formed of two doctors of Sports Science and three professional physical conditioning trainers. The questionnaire validity was verified through an initial pilot study with a reduced group of soccer players of different standard levels and sex $(\mathrm{N}=20)$. After this pilot study, no modifications were required. The questionnaire consisted of one open and 19 closed questions, and included two sections: (1) descriptive data of the soccer players and their personal situation during COVID-19, and (2) training habits during the confinement. The questions were posed with Likert scales $0-10$, multiple options, yes/no questions and questions about the number of hours of training dedicated to the different contents on a $0-8$ scale or more training hours/week, ranging from 0.5 to 1 hour (Woloshin, Schwartz, Byram, Fischhoff, \& Welch, 2000).

\section{Statistical analysis}

Statistical analysis was performed with the IBM SPSS Statistics program (SPSS IBM, Chicago, IL, USA), version 26.0. The analysis of the covariance showed neither significant differences nor associations between the men's first, second and third division; therefore, the statistical analysis was carried out considering these three categories as a single group. Equally, it also did not show significant differences or associations between the categories of female first and second division; therefore, the statistical analysis was carried out considering these two categories as a single group. The normality of data distribution was verified with the Kolmogorov-Smirnov test. The variables studied did not follow normality. Differences were studied using the Mann-Whitney U test. Effect sizes (d) were calculated to assess the practical significance of the differences and were interpreted as small $(\mathrm{d} \geq$ $.01)$, moderate $(\mathrm{d} \geq .06)$, and large $(\mathrm{d} \geq .14)$ (Cohen, 1992). Significance was accepted at $\mathrm{p}<.05$.

\section{Results}

\section{Changes in daily habits during the confinement}

Analysed data indicated that the level of change in habits and routine shown was $6.0( \pm 2.4)$ in men and $6.7( \pm 1.9)$ in women $(\mathrm{p}<.044)$. The level of 
nutrition change shown in women was $4.6( \pm 2.9)$ and $3.5( \pm 2.5)(\mathrm{p}<.020)$ in men. These results are established on a scale from 0 (no change) to 10 (maximum possible change).

\section{Training volume during the confinement}

The number of weekly training sessions during the confinement was $6.8( \pm 2.2)$ in men and 5.5 $( \pm 2.0)$ in women $(\mathrm{p}<.000)$. The hours of weekly training during the confinement were 7.9 hours $( \pm$ $5.3)$ in men and 7.6 hours $( \pm 4.7)$ in women $(p<.254)$.

\section{Importance of the training program contents during the confinement}

Table 1 shows the degree of importance given to the training program contents during the confinement staged by the soccer players on a Likert scale from 0 to 10 points $(0=$ not important, $10=$ very important). Strength training, flexibility, or range of motion (ROM) training were the contents with greater importance to athletes during this period. However, significant differences were found in psychological training between male and female athletes $(\mathrm{p}<.05)$.

\section{Hours per week dedicated to strength, endurance, speed, alternative care, and technical-tactical contents during the confinement}

Figure 1 shows mean, standard deviation and $\mathrm{p}$ value of the comparison between men and women in the number of hours dedicated to training of different strength contents by professional soccer players during the confinement. No differences were found.

Table 2 shows the number of hours of training related to endurance, speed and technical-tactical contents practiced by professional soccer players (men and women) during the confinement. Except for high intensity and endurance power circuits, significant differences were found in endurance training between male and female professional players $(\mathrm{p}<.05)$. Male soccer players spent significantly more hours of speed training practicing sprints $(p<.01)$ as shown in Table 2. Female soccer players spent significantly more time practicing group dynamics, challenges, alternative training and directed activities during the confinement.

Table 1. Degree of importance given to the different contents of the training program during confinement, valued by the soccer players on a scale of 0 to 10 points $(0=$ not important and $10=$ very important $)$

\begin{tabular}{lcccc}
\hline & Men $(155)$ & Women $(63)$ & $\mathrm{p}$ & $\mathrm{d}$ \\
\hline Strength & $7.9( \pm 2.1)$ & $7.8( \pm 2.2)$ & .890 & - \\
\hline Endurance & $6.9( \pm 2.6)$ & $6.8( \pm 2.5)$ & .649 & - \\
\hline Speed & $5.9( \pm 2.8)$ & $5.4( \pm 3.0)$ & .282 & - \\
\hline Technical-tactical & $3.6( \pm 3.2)$ & $4.3( \pm 3.0)$ & .129 & - \\
\hline Psychology & $4.1( \pm 3.4)$ & $5.3( \pm 3.4)$ & .013 & 0.35 \\
\hline Nutrition & $6.8( \pm 3.1)$ & $6.3( \pm 3.5)$ & .398 & - \\
Flexibility and ROM & $7.3( \pm 2.5)$ & $6.7( \pm 2.5)$ & .151 & - \\
\hline
\end{tabular}

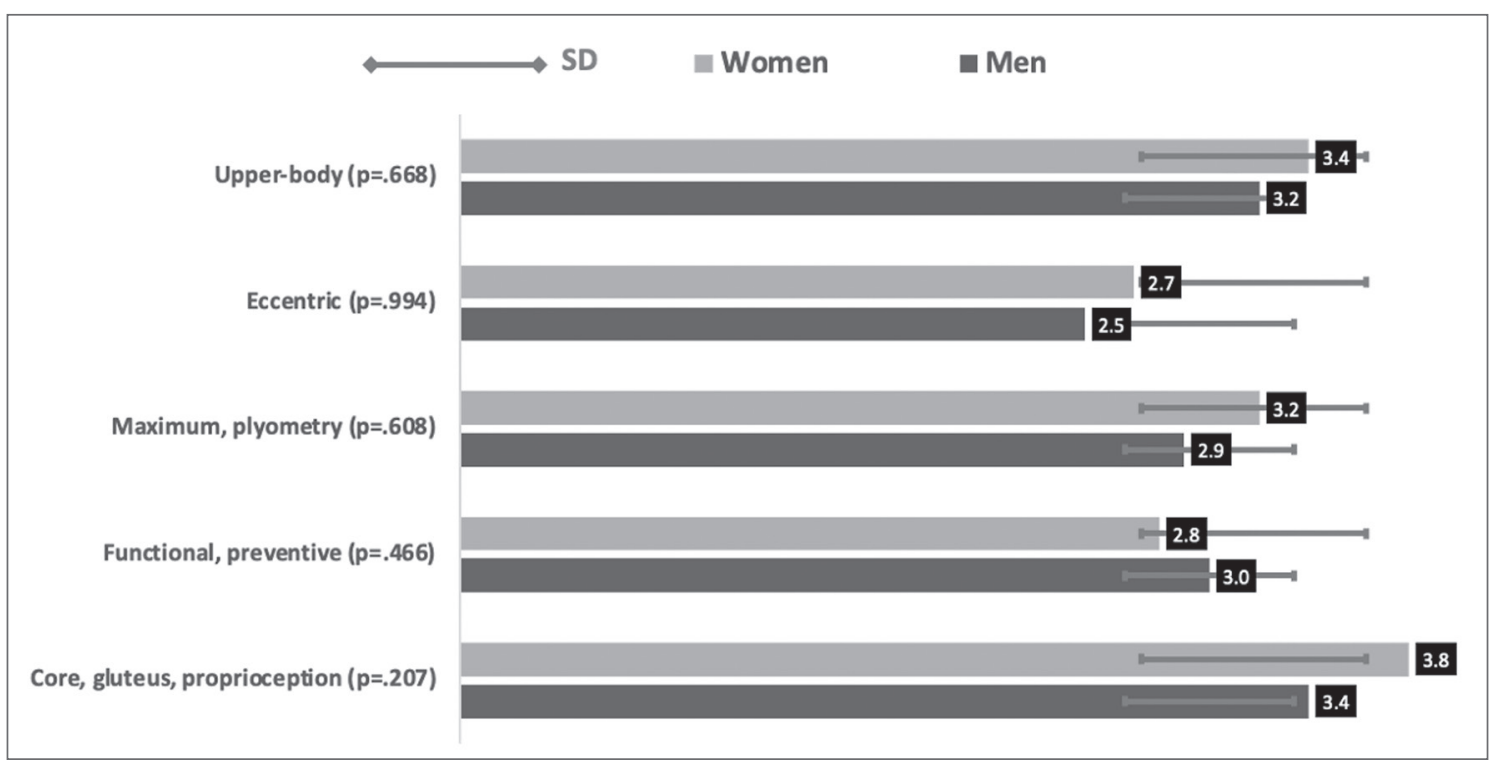

Figure 1. Number of hours devoted to training of different strength contents by professional soccer players (men and women) during confinement. 
Table 2. Number of hours devoted to training of different endurance, speed, and technical-tactical contents by professional soccer players (men and women) during confinement

\begin{tabular}{lcccc}
\hline Endurance training & Men (155) & Women (63) & $p$ & $\mathrm{~d}$ \\
\hline $\begin{array}{l}\text { Regenerative training at low intensity on a bike, cross trainer, } \\
\text { treadmill, outdoors... }\end{array}$ & $1.5( \pm 1.9)$ & $1.3( \pm 2.1)$ & .015 & 0.09 \\
\hline $\begin{array}{l}\text { Continuous training on a bicycle, cross trainer, treadmill, } \\
\text { outdoors ... }\end{array}$ & $1.9( \pm 2.0)$ & $1.2( \pm 1.9)$ & .001 & 0.30 \\
\hline $\begin{array}{l}\text { Intermittent or variable training alternating high and low intensity } \\
\text { on a bicycle, cross trainer, treadmill, outdoors ... }\end{array}$ & $2.1( \pm 2.1)$ & $1.1( \pm 1.8)$ & .000 & 0.51 \\
\hline High intensity and endurance power circuits & $2.9( \pm 2.3)$ & $2.9( \pm 2.3)$ & .876 & - \\
\hline Repetition of sprint races & $1.3( \pm 1.9)$ & $0.8( \pm 1.7)$ & .003 & 0.21 \\
\hline Speed training & & & .797 & - \\
\hline Coordination / movement frequency & $1.8( \pm 1.9)$ & $2.0( \pm 2.0)$ & .310 & - \\
\hline Accelerations and decelerations & $1.5( \pm 1.8)$ & $1.4( \pm 2.0)$ & .521 & - \\
\hline Agility / changes of direction & $1.4( \pm 1.8)$ & $1.4( \pm 1.9)$ & .745 & - \\
\hline Reaction speed & $1.3( \pm 1.8)$ & $1.1( \pm 1.6)$ & .009 & 0.17 \\
\hline Sprint speed & $1.1( \pm 1.7)$ & $0.8( \pm 1.8)$ & \\
\hline Technical-tactical training & & & .097 \\
\hline Adapted technical-tactical program & $0.6( \pm 1.4)$ & $0.7( \pm 1.1)$ & - \\
\hline Technical-tactical audiovisual material & $0.6( \pm 1.4)$ & $0.6( \pm 0.9)$ & .043 & 0.01 \\
\hline Psychological training & $0.7( \pm 1.4)$ & $0.8( \pm 1.3)$ & .266 & - \\
\hline Group dynamics and challenges & $0.9( \pm 1.5)$ & $1.9( \pm 1.8)$ & .000 & 0.60 \\
\hline Alternative training and directed activities & $1.4( \pm 2.1)$ & $1.7( \pm 2.0)$ & .023 & 0.14 \\
\hline
\end{tabular}

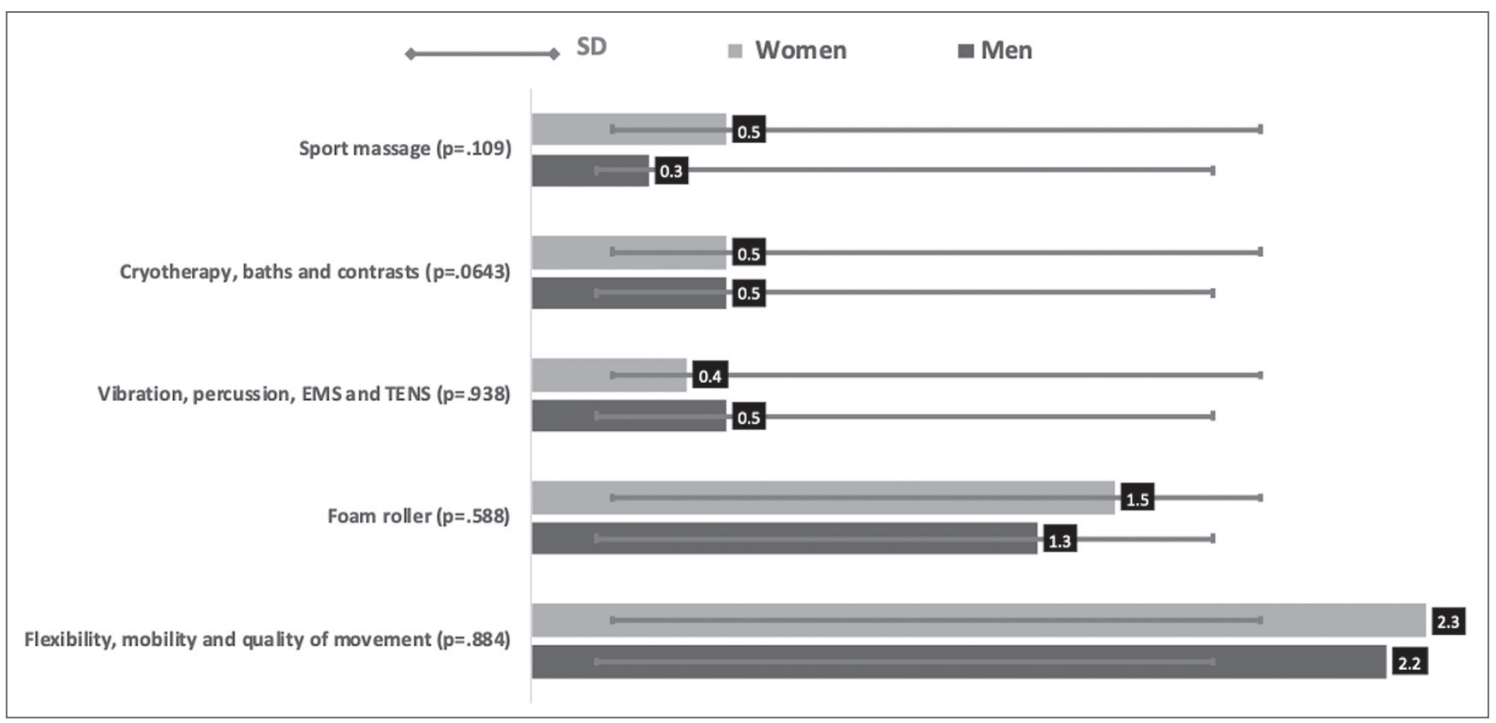

Figure 2. Number of hours devoted to the development of alternative care by professional soccer players (men and women) during confinement.

Figure 2 shows mean, standard deviation and $\mathrm{p}$ value of the comparison between men and women in the number of hours dedicated to the development of alternative care by professional soccer players during the confinement. Differences between the groups were not found.

\section{Resources used in training during the confinement}

Table 3 shows the materials or resources used by professional soccer players (men and women) for the development of training sessions during the confinement.

Results revealed that there was a higher percentage of male soccer players using cardiovascular training machines, whereas female soccer players used more frequently everyday material, soccer training material and new technologies and audiovisual material to train. No significant differences were found in the use of gym equipment, functional training material and signaling, coordination and agility equipment to train during the 
Table 3. Materials or resources used for the development of training sessions during confinement by professional soccer players (men and women)

\begin{tabular}{lccc}
\hline & Men (155) & Women (63) & $\mathrm{p}$ \\
\hline Cardiovascular training machines (exercise bike, treadmill, elliptical trainer, ...) & $65.2 \%$ & $30.2 \%$ & .000 \\
\hline $\begin{array}{l}\text { Gym equipment (plates, bars, } \\
\text { dumbbells, strength machines, ..) }\end{array}$ & $55.5 \%$ & $50.8 \%$ & .712 \\
\hline $\begin{array}{l}\text { Functional training material (resistance bands, medicine balls, TRX, grips, } \\
\text { weights, ..) }\end{array}$ & $87.1 \%$ & $88.9 \%$ & .716 \\
\hline $\begin{array}{l}\text { Unstable training material (bosu, Ltball,) } \\
\text { Everyday material (backpacks, water bottles, calisthenics equipment, ...) }\end{array}$ & $38.7 \%$ & $42.9 \%$ & .571 \\
\hline $\begin{array}{l}\text { Signaling, coordination and agility equipment (marking cones, pole, coordination } \\
\text { hurdles, ladders, ..) }\end{array}$ & $34.8 \%$ & $33.3 \%$ & .000 \\
\hline $\begin{array}{l}\text { Alternative care material (foam roller, electrostimulator, EMS, TENS, percussion } \\
\text { gun, ...) }\end{array}$ & $63.2 \%$ & $54.0 \%$ & .205 \\
\hline $\begin{array}{l}\text { Soccer training material } \\
\text { (balls, goals, ..) }\end{array}$ & $40.6 \%$ & $58.7 \%$ & .015 \\
\hline New technologies and audiovisual material & $23.9 \%$ & $41.3 \%$ & .010 \\
\hline
\end{tabular}

confinement between male and female professional soccer players.

\section{Discussion and conclusions}

The objective of this study was to describe training habits of Spanish professional soccer players of both sexes during the COVID-19 confinement. To date, there is no scientific evidence for the training habits developed by athletes during a state of emergency or the confinement itself caused by COVID-19.

Urgent containment of the virus in the shortest possible time has been the priority for public health (Chen, et al., 2020). However, the prescriptions and recommendations by health authorities in relation to daily exercise routines and physical activity to maintain or increase population health have been scarce (Chen, et al., 2020; Jukic, et al., 2020) despite the fact that there is a clear scientific evidence demonstrating the benefit of regular physical activity in the primary and secondary prevention of diabetes, hypertension, cancer (particularly breast and colon cancer), depression, osteoporosis, and dementia (Sallis, 2009). Therefore, considering this isolation measure as a favourable means to prevent infection spread could have unwanted physical and mental consequences on the general population and athletes in particular (Chen, et al., 2020; Jukic, et al., 2020; Sallis, 2009).

The results of this study showed that athletes were forced to significantly change their daily routines, as other research already warned (Chen, et al., 2020; Jukic, et al., 2020). Training habits were also substantially altered due to the impossibility of carrying out regular sports practice due to the confinement. Asín-Izquierdo, Gutiérrez-García, Zapardiel and Chena (2021) show that training structure during the COVID-19 confinement was limited by contextual circumstances. The conse- quences of this situation could accelerate the partial or complete loss of training-induced anatomical, physiological, and functional adaptations (Mujika \& Padilla, 2000). According to the principle of reversibility, the adaptations obtained throughout the season are 'semi-permanent' and last as long as the stimulus remains (Mujika \& Padilla, 2003), accelerating a detraining process (Mujika \& Padilla, 2000, 2003; Suarez-Arrones, et al., 2019). All soccer players in the study participated in a prescribed training program regardless of gender. Although the effects of athletes' detraining are evident during off season despite the prescription made by physical trainers for the transitional period (Requena, et al., 2017; Sotiropoulos, Travlos, Gissis, Souglis, \& Grezios., 2009; Suarez-Arrones, et al., 2019), these changes were significantly less pronounced in those professional players who adhered to a prescribed training with respect to those who did nothing (Sotiropoulos, et al., 2009; Suarez-Arrones, et al., 2019). These findings could justify footballers' awareness about individual training during this period.

Considering that soccer training specificity is based on respecting movement patterns and the internal logic of the game, the soccer players completely reduced this specific training during the confinement. Therefore, one would expect the appearance of unwanted mechanical effects typical of sport (Jukic, et al., 2020; Mujika \& Padilla, 2000, 2003). As a consequence of this confinement situation, nonspecific and individual training was the most used to counteract the effects of detraining. According to scientific literature, this generic training could increase the ratio of perceived exertion (RPE) in soccer players (Casamichana, Castellano, Calleja-Gonzalez, San Román, \& Castagna, 2013). The subjective perception of athletes is considered an effective method to control training effort. Strong correlations have been found 
between different quantification methods to determine internal and external load through RPE and training time (session-RPE) (Casamichana, et al., 2013; Ehrmann, Duncan, Sindhusake, Franzsen, \& Greene, 2016; Malone, et al., 2015). These findings and the impossibility of interacting with soccer players could justify the importance of controlling the individual training load of soccer players with the ratio of perceived exertion (RPE) during the COVID-19 confinement (Asín-Izquierdo, et al., 2021). Inadequate training loads are associated with an increased injury rate, decreased individual fitness, and decreased performance (Gabbett, 2016; Gabbett \& Domrow, 2007; Malone, et al., 2015). The need to prescribe individualized or group training programs with which to maximize athletes' adaptations for a coming resumption of the season, while minimizing the cumulative effects of fatigue (Malone, et al., 2015), could explain the results found in this study.

According to the results shown in this study, the most common training contents during the confinement, in both sexes, were mainly based on strength training (7.9 h / week in men and 7.8 in women) and endurance training $(6.9 \mathrm{~h} /$ week in men and 6.8 in women). Strength and endurance training were the main training contents used during this period according to the results obtained in this study. Several studies have shown the benefits obtained by professional footballers in preseason after combining strength training (ST) and high intensity training (HIT) sessions during the transition period (Joo, 2018; Requena, et al., 2017; Sotiropoulos, et al., 2009; Suarez-Arrones, et al., 2019). HIT is one of the most effective methods to improve the condition of athletes. It mainly affects mitochondrial biogenesis, fat oxidation and muscle attenuation capacity (Buchheit \& Laursen, 2013a; Hoffmann, Reed, Leiting, Chiang, \& Stone, 2014). However, not all footballers had the possibility to train high intensity intermittent endurance due to the lack of material and spatial resources. However, the training stimulus when programming HIT includes cardiovascular work, anaerobic glycolytic energy contribution, acute neuromuscular load and musculoskeletal tension (Buchheit \& Laursen, 2013a, 2013b). The space limitation and the scientific evidence related to this training methods were probably the main reasons why coaches used them to improve players' fitness. This could explain that the greater number of hours of endurance training in both sexes has been carried out through resistance and high intensity power circuits, with the aim of training metabolic pathways through neuromuscular exercises of different tension with one's own body weight or with light loads, as proposed by Chen et al. (2020). Statistically significant differences were found between both sexes in terms of regenerative resistance training, continuous training, intermittent or variable training and repetition of sprint races, with men showing the highest training volume. Players of both sexes showed a high percentage of training contents aimed at injury prevention. Considering the reduction of the conditioning-dependent properties of tissues, especially tendons and muscles, as well as the mismatches of neuromuscular control, several authors have suggested the need to provide different types of stresses (Buchheit \& Laursen, 2013b; Gajhede-Knudsen, Ekstrand, Magnusson, \& Maffulli, 2013) to maintain structural adaptations, and different types of speeds and movements to guarantee the functionality of the tendon (Kubo, Ikebukuro, Yata, Tsunoda, \& Kanehisa, 2010). Speed was one of the contents to which less importance was given in the training programs, although it is known that a single week of training cessation can reduce the performance of speed resistance in trained soccer players (Joo, 2018). Although there were no significant differences in the degree of importance given to speed training between men and women, the results of this study showed that the volume of speed training realized through sprinting performed by men was significantly higher than by women $(\mathrm{p}<.009)$. This could be due to the difficulty of developing speed training if the necessary distance is not available.

Jukic et al. (2020) suggest that the situation caused by the virus SARS-CoV-2 is presented as an opportunity to implement programs for the development of certain physical abilities, for which an athlete, in team sports, does not have enough time under the regular periodization regime. The results found in this study showed a high frequency of mobility, core and glute activation training. Central and functional mobility and stabilization training should be included in conditioning programs, especially for injury prevention (Okada, Huxel, \& Nesser, 2011), which were included in the programs followed by the participants. McCall et al. (2014) showed that the majority of professional teams established a 24-hour rest period between prescribed programs for the prevention of injuries and strength optimization training for the lower limbs. However, a high percentage of professionals addressed both strategies in the same session.

The perceived relevance of technical-tactical aspects was the lowest of the program (3.6 and 4.3 out of 10 , respectively in men and women). This is probably related to the non-possibility of developing specific training on a soccer field. Regarding the contents of the technical-tactical training, a greater number of hours of dynamics and group sessions were developed significantly in women than in men. According to the information from the relevant authorities, men's soccer competitions were highly likely to resume. However, there were major problems with women's national football. The best way to work on these contents is through the real 
presence and interaction of the players on the pitch. Considering the return to normal training where coaches can dedicate time to technical-tactical training on the field, this type of training was not a priority during the confinement.

Finally, Jukic et al. (2020) established the need to organize strength and conditioning training in a personalized way during lockdown at home, considering the material and spatial resources available to athletes. This may be the explanation through which the poorly defined results in this study are understood in relation to the training contents. Male and female professional soccer players did not have the same spatial and material resources to develop training in the same way. Men had significantly greater use of training machines while women made more use of everyday material, soccer training material, new technologies or audio-visual material. This could be due to differences in economic resources between the sexes.

The results of this study show the real intervention developed in the context analysed. This specific intervention differs from the general considerations raised by other publications (Chen, et al., 2020; Jukic, et al., 2020). For the interpretation of these data, it is suggested that the exceptional emergency situation in which both the study and the trainings were carried out be taken into account. The situation required high levels of uncertainty to design training programs due to the variability of contexts and the insecurity in resuming the activity. The magnitude of changes in training-induced adaptations after detraining is different depending on the level of previous physical fitness and the duration of activity cessation or insufficient training (Mujika $\&$ Padilla, 2000, 2003). Therefore, this information could justify that all the soccer players who participated in this study carried out physical activity in their respective homes.

In conclusion, the findings of this study showed useful information related to training habits in professional soccer players for both sexes that could be considered as reference values for coaches or physical trainers and represent the starting point to be used globally with athletes in transition or exceptional periods.

This study generates new knowledge that could be used to address training planning in specific periods of the year (transition periods, Christmas holidays and other emergency periods).

\section{References}

Asín-Izquierdo, I., Gutiérrez-García, L., Zapardiel, J.C., \& Chena, M. (2021). Structure of the training program during the COVID-19 confinement in Spanish professional football, a coach survey. The Physician and Sportsmedicine, [in press]. doi: 10.1080/00913847.2021.1932633

Buchheit, M., \& Laursen, P.B. (2013a). High-intensity interval training, solutions to the programming puzzle. Part I: Cardiopulmonary emphasis. Sports Medicine, 43(5), 313-338. doi: 10.1007/s40279-013-0029-x

Buchheit, M., \& Laursen, P.B. (2013b). High-intensity interval training, solutions to the programming puzzle. Part II: Anaerobic energy, neuromuscular load and practical applications. Sports Medicine, 43(10), 927-954. doi: 10.1007/s40279-013-0066-5

Casamichana, D., Castellano, J., Calleja-Gonzalez, J., San Román, J., \& Castagna, C. (2013). Relationship between indicators of training load in soccer players. The Journal of Strength and Conditioning Research, 27(2), $369-374$. doi: 10.1519/JSC.0b013e3182548af1

Chen, P., Mao, L., Nassis, G.P., Harmer, P., Ainsworth, B.E., \& Li, F. (2020). Coronavirus disease (COVID-19): The need to maintain regular physical activity while taking precautions. Journal of Sport and Health Science, 9(2), 103-104. doi: 10.1016/j.jshs.2020.02.001

Cohen, J. (1992). Quantitative methods in psychology. American Psychological Association, 112(1), 155-159.

Corsini, A., Bisciotti, G.N., Eirale, C., \& Volpi, P. (2020). Football cannot restart soon during the COVID-19 emergency! A critical perspective from the Italian experience and a call for action. British Journal of Sports Medicine, 54(20), 1186-1187. doi: 10.1136/bjsports-2020-102306

Ehrmann, F.E., Duncan, C.S., Sindhusake, D., Franzsen, W.N., \& Greene, D.A. (2016). GPS and injury prevention in professional soccer. The Journal of Strength and Conditioning Research, 30(2), 360-367. doi: 10.1519/ JSC.0000000000001093

Gabbett, T.J. (2016). The training - injury prevention paradox: Should athletes be training smarter and harder? British Journal of Sports Medicine, 50(5), 273-280. doi: 10.1136/bjsports-2015-095788

Gabbett, T.J., \& Domrow, N. (2007). Relationships between training load, injury, and fitness in sub-elite collision sport athletes. Journal of Sports Sciences, 25(13), 1507-1519. doi: 10.1080/02640410701215066

Gajhede-Knudsen, M., Ekstrand, J., Magnusson, H., \& Maffulli, N. (2013). Recurrence of achilles tendon injuries in elite male football players is more common after early return to play: An 11-year follow-up of the UEFA Champions League injury study. British Journal of Sports Medicine, 47(12), 763-768. doi: 10.1136/bjsports-2013-092271 
Hoffmann, J.J.J., Reed, J.P., Leiting, K., Chiang, C., \& Stone, M.H. (2014). Repeated sprints, high-intensity interval training, small-sided games: Theory and application to field sports. International Journal of Sports Physiology and Performance, 9(2), 352-357. doi: 10.1123/ijspp.2013-0189

Joo, C.H. (2018). The effects of short term detraining and retraining on physical fitness in elite soccer players. Plos One, 13(5), e0196212. doi: 10.1371/journal.pone.0196212

Jukic, I., Calleja-González, J., Cos, F., Cuzzolin, F., Olmo, J., Terrados, N., Njaradi, N., Sassi, R., Requena, B., Milanovic, L., Krakan, I., Chatzichristos, K., \& Alcaraz, P. E. (2020). Strategies and solutions for team sports athletes in isolation due to COVID-19. Sports, 8(4), 56. doi: 10.3390/sports8040056

Kubo, K., Ikebukuro, T., Yata, H., Tsunoda, N., \& Kanehisa, H. (2010). Time course of changes in muscle and tendon properties during strength training and detraining. The Journal of Strength and Conditioning Research, 24(2), 322-331. doi: 10.1519/JSC.0b013e3181c865e2

Malone, J.J., Di Michele, R., Morgans, R., Burgess, D., Morton, J.P., \& Drust, B. (2015). Seasonal training load quantification in elite English Premier League soccer players. International Journal of Sports Physiology and Performance, 10(4), 489-497. doi: 10.1123/ijspp.2014-0352

McCall, A., Carling, C., Nedelec, M., Davison, M., Gall, F.L., Berthoin, S., \& Dupont, G. (2014). Risk factors, testing and preventative strategies for non-contact injuries in professional football: Current perceptions and practices of 44 teams from various premier leagues. British Journal of Sports Medicine, 48(18), 1352-1357. doi: 10.1136/ bjsports-2014-093439

Mujika, I., \& Padilla, S. (2000). Detraining: Loss of training-induced physiological and performance adaptations. Part I. Sports Medicine, 30(2), 79-87. doi: 10.2165/00007256-200030020-00002

Mujika, I., \& Padilla, S. (2003). Physiological and performance consequences of training cessation in athletes: Detraining. In W. Frontera (Ed.), Rehabilitation of sports injuries: Scientific basis. The Encyclopaedia of Sports Medicine, Vol. $X$ (pp. 117-143). Blackwell Publishing.

Okada, T., Huxel, K.C., \& Nesser, T.W. (2011). Relationship between core stability, functional movement, and performance. The Journal of Strength and Conditioning Research, 25(1), 252-261. doi: 10.1519/JSC.0b013e3181b22b3e

Requena, B., García, I., Suárez-Arrones, L., Sáez de Villarreal, E., Naranjo-Orellana, J., \& Santalla, A. (2017). Off-season effects on functional performance, body composition, and blood parameters in top-level professional soccer players. Journal of Strength and Conditioning Research, 31(4), 939-946. doi: 10.1519/JSC.0000000000001568

Sallis, R.E. (2009). Exercise is medicine and physicians need to prescribe it!. British Journal of Sports Medicine, 43(1), 3-4. doi: 10.1136/bjsm.2008.054825

Sotiropoulos, A., Travlos, A.K., Gissis, I., Souglis, A.G., \& Grezios, A. (2009). The effect of a 4-week training regimen on body fat and aerobic capacity of professional soccer players during the transition period. The Journal of Strength and Conditioning Research, 23(6), 1697-1703. doi: 10.1519/JSC.0b013e3181b3df69

Suarez-Arrones, L., Lara-Lopez, P., Maldonado, R., Torreno, N., Hoyo, M.D., Nakamura, F.Y., Di Salvo, V., \& MendezVillanueva, A. (2019). The effects of detraining and retraining periods on fat-mass and fat-free mass in elite male soccer players. PeerJ, 7, e7466. doi: 10.7717/peerj.7466

Tavares-Lima, C.K., de Medeiros-Carvalho, P.M., Silva-Lima, I.A.A., de Oliveira-Nunes, J.V.A., Saraiva, J.S., de Souza, R.I., Lima-da Silva, C.G., \& Rolim-Neto, M.L. (2020). The emotional impact of coronavirus 2019-nCoV (new coronavirus disease). Psychiatry Research, 287, 112915. doi: 10.1016/j.psychres.2020.112915

Valencia, D.N. (2015). Brief review on COVID-19: The 2020 pandemic caused by SARS-CoV-2. Cureus, $12(3)$, e7386. doi: 10.7759/cureus.7386

Woloshin, S., Schwartz, L.M., Byram, S., Fischhoff, B., \& Welch, H.G. (2000). A new scale for assessing perceptions of chance: A validation study. Medical Decision Making, 20(3), 298-307. doi: 10.1177/0272989X0002000306

Submitted: March 1, 2021

Accepted: November 29, 2021

Published Online First: December 9, 2021
Correspondence to:

Iván Asín-Izquierdo

Faculty of Medicine and Health Sciences, Department of Biomedical Sciences

University of Alcalá, Madrid, Spain

Ctra. Madrid-Barcelona, Km. 33,600

28871 Alcalá de Henares

Email: ivanasizq@gmail.com

Phone: +34627 526847

\section{Limitations}

Due to the special situation of confinement, the questionnaire was done in an online mode to make it possible to be filled in by the participants. Despite the number of participants is not high, we consider it being a relevant representation of the group (professional soccer players). 